\title{
Interaction Design for Behavioural Change
}

\author{
Paul Doney \\ School of Computing and \\ Creative Technologies \\ Leeds Metropolitan \\ University LS6 3HE \\ p.doney@leedsmet,.ac.uk
}

\author{
Marc Fabri \\ School of Computing and \\ Creative Technologies \\ Leeds Metropolitan \\ University LS6 3HE \\ m.fabri@leedsmet,.ac.uk
}

\author{
David Moore \\ School of Computing and \\ Creative Technologies \\ Leeds Metropolitan \\ University LS6 3HE \\ d.moore@leedsmet,.ac.uk
}

\begin{abstract}
This paper provides an overview of the current research activity at Leeds Metropolitan University which relates to the application of ICT to the promotion of health and wellbeing. In doing so the common threads of interaction/interface design and fostering behaviour change are identified as an emerging area of interest. The current wellbeing and weight management projects are identified as potential vehicles for further formal investigation.
\end{abstract}

Keywords; User Experience, Mobile Tools, Behaviour Change, Retention, Wellbeing, Obesity, Autism

\section{INTRODUCTION}

In this paper we review our current work in the School of Computing and Creative Technologies at Leeds Met concerning the use of ICT to support sustainable living and then briefly outline our plans for the future development of this work.

\section{ICT AND DISABILITY}

We have held a series of one day annual conferences concerning disability in educational contexts (Moore et al 2012). Three recurring topics are perhaps of relevance to the $\mathrm{HCl}$ workshop, namely ICT and autism, computer simulations of disabilities and the use of eye tracking technology with people with profound multiple learning difficulties.

\subsection{ICT and autism}

We argue that computer-based learning systems can be helpful for people with autism and that the use of autism-specific systems may play a beneficial role in the education of students with autism (Moore et al 2005). We have identified, however, a number of weaknesses currently in the research concerning computer systems for people with autism (Moore 2012). One of these weaknesses is that most work to date has investigated the technology for people with Asperger Syndrome (generally seen as a mild form of autism).

Very little attention has been paid to the important issue of whether and how people with severe autism might benefit from the technology. Our recent work involves research designed to begin to address this weakness (Elzuki and Cooper 2012).

\subsection{Simulating disabilities}

Other colleagues have been investigating the use of a computer aided test that has been developed to help university staff to become aware of issues faced by students with disabilities (Gray et al 2012). This software is designed to demonstrate some of the accessibility issues associated with a range of disabilities, such as visual, hearing, physical and cognitive impairments. In addition, the test provides advice on good practice and website links to further relevant information. The test has been used to train university staff in disability issues and the evidence suggests that it is a successful staff development tool.

Staff reactions to the test have been positive and feedback indicates that using the computer aided simulation has generated an increased awareness of disability issues and an understanding by staff of the need to make changes to their future practice to improve the educational experience of disabled students.

\subsection{Eye tracking}

Eye tracking technology in general (Renshaw et al 2008, Marchant et al 2009) and its use as an educational aid for people with profound multiple learning difficulties (PMLD) in particular (Renshaw et al 2012) is another current research area. The argument is that the non-invasive eye tracking technology may provide those with PMLD with a 
richer way of communicating, in that it records information as to where a participant is actually looking, thus providing a more precise alternative to the traditional method of pointing at symbols. Field work suggests that the eye tracking system gives immediate feedback on symbol recognition performance which not only enables teachers to adapt their teaching strategies but also facilitates a richer interactive experience between them and their student.

\section{3. "MY WELLBEING"}

The Leeds Metropolitan University's wellbeing excellence programme, which was implemented in 2009, included the development of a website (mywellbeing.org) to provide employees with guidance on 230 health and wellbeing related topics (IDS 2012). It is claimed (Leeds Met 2012) that since implementing this programme, the University has saved $£ 75,000$ a year in wages, with stress-related absence down by $16 \%$ and the accident incident rate standing at just 64.7 per 100,000 employees, compared to the sector average of 325

The task-based advice is built around every-day tasks such as dealing with emails, writing reports and attending meetings. As well as guidance concerning how to manage these activities, related health advice is offered such as relaxation and anger management. The system has a number of clients across the public and private sector, reaching over 200,000 employees and their families.

Further, the Northern Technology Institute (NTI), which is part of Leeds Met, has developed a mobile app version, "My Wellbeing". The app is available for iPhone, Android and Blackberry devices and is intended to be an online wellbeing resource. The app is currently being updated and as part of that update full consideration is being given to how use of the app might be tracked to provide data to drive future improvements and research opportunities.

\section{IT AND SPORT}

In a collaboration with the Carnegie Faculty, colleagues are investigating the effects of technology specifically designed for use in physical activity, in particular the iPod Nike+ kit, on individuals' activity levels. The work paper focuses on the extensively used transtheoretical model (TTM) of change, which has been used in previous studies as a lens for examining the adoption of physical activity.
A small pilot study, using information from a questionnaire and convenience data set, has been conducted, to gain an insight into the use of the technology with regard to physical activity and the transtheoretical model of change (Trevorrow, in press). The data suggests that there is some possibility for the technology to advance individuals through the TTM stages of change for physical activity, but only if they are already motivated to start exercising. More research, however, is required in order to make any conclusive claims.

\section{5. “MORE LIFE" - TACKLING OBESITY}

More Life is a spin-off company from Leeds Met focussed on tackling obesity. It offers weight management programmes to individuals, families, communities and workplaces. The programmes are heavily reliant on using ICT as a vehicle for education, outcome tracking and fostering behavioural change. The company is currently supporting 8000 adults and 3000 children.

The web platform is being developed on an ongoing basis and a new more immersive virtual environment is being explored in conjunction with Imperial College. At present no formal research activity has been undertaken concerning the usability and effectiveness of the current platform, although the company itself emerged from successful research activity in the Leeds Met Carnegie Sport Faculty (Gately, 2005). More Life is seeking collaborators to address this and initiate research that will lead to improved engagement with the platform and consequently better overall outcomes.

\section{FUTURE PLANS}

All the work discussed thus far addresses, we believe, the issue of "behaviour change" to some extent. The autism work hopes to encourage small but important changes in the behaviour of people with autism, the simulation work aims to change academics' behaviour towards assessment, the eye tracking work aims to change the reading behaviour of the young people and the practice of their teachers, "My Wellbeing" aims to change the behaviour of staff, the IT and sport work aims to encourage people to take up and persist with physical activity and "More Life" aims to change eating and exercise behaviour.

The work presented here can be categorised as those projects that have been approached primarily through the lens of interaction design (section 2) and those that stem primarily from research associated with health and fitness. Systems in the 
latter category being built implicitly on models of behaviour change in the case of My WellBeing and More Life or explicitly in the case of the IT and Sport investigation.

The two areas of study and indeed the projects discussed have their origins in separate domains, but at the intersection there is increasing evidence of cross-disciplinary activity and research. For example from the interaction design perspective Dan Lockton (2012) has published "Design with Intent: A design pattern toolkit for environmental \& social behaviour change" and Webb et al (2010) devised a new coding scheme for assessing mode of delivery in Internet-based interventions to support their study of theoretically grounded health behaviour change systems.

Our plans are to explore this intersection in particular:

- What are the characteristics of effective interaction design in the context of systems devised to promote behavioural change?

- In what ways might the existing models of behaviour change need to be supplemented to produce a model explicitly targeted at computer mediated systems?

We have two potential vehicles to directly support these research aims, namely the My WellBeing website/mobile app and the More Life platform. Using these existing projects and the work of Lockton(2012) and Michie et al (2011) we aim to systematically explore the interplay between interaction design and behaviour change and determine the extent to which the systems reflect current theoretical models and any implications of system use for these models.

\section{REFERENCES}

Elzuki S and Cooper B (2012) Understanding and enhancing emotional literacy for severely autistic students through the use of computers. In D Moore, A Gorra, M Adams, J Reaney, H Smith (eds) Disabled Students in Education: Technology, Transition and Inclusivity, IGI Press, Hershey

Fogg BJ (2009) The Behavior Grid: 35 Ways Behavior Can Change [Internet] Available from:<http://www.behaviorgrid.org/> [Accessed 18th July 2012].

Gatley, P Cooke, C, Barth, J, Bewick, B, Radley, D
Hill, A (2005) "Children's Residential Weight-Loss Programs Can Work: A Prospective Cohort Study of Short-Term Outcomes for Overweight and Obese Children", Pediatrics Vol. 116 No. 1 July 1, 2005 pp. $73-77$

Gray J, Harrison G, Gorra A, Sheridan-Ross J (2012) Using a computer aided test to raise awareness of disability issues amongst university teaching staff. In D Moore, A Gorra, M Adams, J Reaney, H Smith (eds) Disabled Students in Education: Technology, Transition and Inclusivity, IGI Press, Hershey

IDS (2012), Employee health \& wellbeing IDS HR in Practice 958, IDS, Leeds Met 2012

Lockton D (2012) "Design with Intent: A design pattern toolkit for environmental \& social behaviour change" Ph.D. Thesis, Brunel University

Marchant, P.; Raybould, D.; Renshaw, T; Stevens, R. (2009). Are you seeing what I'm seeing: An eyetracking evaluation of dynamic scenes. Digital Creativity, 20(3): 153-163, Taylor \& Francis

Michie S, van Stralen M, West R (2011) "The behaviour change wheel: A new method for characterising and designing behaviour change interventions". Implementation Science [Internet] Available from:

$<$ http://www.implementationscience.com/co ntent/6/1/42> [Accessed 18th July 2012].

Moore D (2012) Computer-based learning systems for people with autism. In D Moore, A Gorra, M Adams, J Reaney, H Smith (eds) Disabled Students in Education: Technology, Transition and Inclusivity, IGI Press, Hershey

Moore D, Gorra A, Adams M, Reaney J, Smith H (eds) Disabled Students in Education: Technology, Transition and Inclusivity, IGI Press, Hershey

Moore D, Cheng Y, McGrath P, Powell N J, (2005) Collaborative virtual environment technology for people with autism. Focus on Autism and Other Developmental Disorders, 20, 231-243, Hammill Institute on Disabilities, Sage Journals

Renshaw T, Boullier B, Geddes S, and 
Moore A (2012) An Assessment of Eye Tracking as an Educational Aid for People with Profound Multiple Learning Difficulties (PMLD). In D Moore, A Gorra, M Adams, J Reaney, H Smith (eds) Disabled Students in Education: Technology, Transition and Inclusivity, IGI Press, Hershey

Renshaw, T; Stevens, R; Denton, P D. (2008).

Understanding games interaction through eyetracking: from user learning to new business model development, 38th SAGSET Conference, Nottingham. 2008.

Trevorrow, $\mathrm{P}$ (in press) Technology running the world: the iPod/Nike+ kit and levels of physical activity. In Press for Society \& Leisure

Webb T, Joseph J, Yardley L, Michie S (2010) "Using the Internet to Promote Health Behavior Change: A Systematic Review and Meta-analysis of the Impact of Theoretical Basis, Use of Behavior Change Techniques, and Mode of Delivery on Efficacy". Journal of Medical Internet Research vol 12(1):e4 